THE CANADIAN JOURNAL OF AUTISM EQUITY LA REVUE CANADIENNE DE L'ÉQUITÉ EN MATIÈRE D'AUTISME \begin{tabular}{l|l|l} 
VOLUME 1 & ISSUE 1 & APRIL 2021
\end{tabular}

\title{
Equity: What Model Should We Use When We Talk About Autism?
}

Rebekah Kintzinger, Canadian Autism Spectrum Disorder Alliance, Canada 


\title{
Equity: What Model Should We Use When We Talk About Autism?
}

\author{
Rebekah Kintzinger ${ }^{1}$ iD
}

\begin{abstract}
In the Canadian disability rights movement, with regards to autism specifically, there has been a shift towards recognizing what is called a social model of disability. Through this movement, there has been a desire to incorporate that model into practice in governments, institutions, and healthcare. This desire also stems from advocate-centric and first-voice communities, where disabilities like autism are not viewed through a deficit-based lens. This article aims to discuss the often polarizing social and medical models of disability, comparing their uses in the disability world while weighing their respective benefits. Finally, an alternative model of disability that intersects these models is discussed as an alternative. This model is called the International Classification of Functioning, which recognizes three levels that impair a disabled person: the body, the person, and the environment. It is from this focus that policy can be developed to answer

the calls of the pan-disability movement; to provide equitable changes across services and domains that are rightly deserved for Autistic and disabled people. Résumé
\end{abstract}

Dans le mouvement canadien de défense des droits des personnes handicapées, en particulier en ce qui concerne l'autisme, il y a eu une évolution vers la reconnaissance de ce qu'on appelle un « modèle social du handicap ». Ce mouvement a suscité un désir d'incorporer ce modèle dans la pratique des gouvernements, des institutions et des soins de santé. Ce désir découle également des communautés centrées sur les personnes militantes et sur la défense des droits, où les handicaps comme l'autisme ne sont pas perçus à travers l'optique du déficit. Cet article a pour but de discuter des modèles social et médical du handicap, qui sont souvent diamétralement opposés, en comparant leurs utilisations dans le monde du handicap tout en évaluant leurs avantages respectifs. Enfin, nous discutions d'un modèle alternatif du handicap qui recoupe ces modèles en tant que solution de rechange. Ce modèle, appelé la Classification internationale du fonctionnement, reconnaît trois niveaux de handicap chez une personne : le corps, la personne et l'environnement. C'est à partir de cette perspective que l'on peut élaborer une politique qui répond aux appels du mouvement panhandicap, afin d'apporter des changements équitables dans les services et les domaines que les personnes autistes et handicapées méritent à juste titre.

Keywords Autism, Disability Rights, Advocacy Mots clés Autisme, Droits des Personnes Handicapées, Militance

1 Canadian Autism Spectrum Disorder Alliance 
In my journey as an Autistic self-advocate in Canada, I have seen my country struggle with adopting a unified approach to the Autistic community's needs. In Canada, I see service providers, institutions, and the government working from the perspective of a medical model of disability which views the Autistic person as needing to be treated, or cured, or otherwise have a plan in place for their impairments in an attempt to achieve "normality" (Shyman, 2016, p.367). The widely used medical model of disability in Canada involves a disabled person, and them specifically having an abnormality or deficiency. In a medical model of disability, disability is interpreted as negative, and often pathologized as a constellation of deficits while ignoring any inherent strengths or advantages the person might have (Kapp, 2019). It is an area of health where disease is detected, identified, and treated without looking at the person.

For example, in Ontario, one of the main supports for children funded under the Ontario Autism Program is behavioural services, which include Applied Behaviour Analysis (ABA) and its more intensive form of Intensive Behaviour Intervention, aimed at teaching new skills and reducing unwanted behaviours (see Ministry of Children, Community and Social Services, 2019). ABA therapy incorporates the medical model of disability and treats an Autistic person as having a medical problem that interferes with 'normal functioning' (Shyman, 2016). The main goal of ABA therapy in Autistic conditions is to reach an "acceptable" level of normality in social, behavioural, and intellectual functioning (Shyman, 2016).

Often, on social media, I see Autistic and disabled people calling for the acknowledgement of the role that society plays in perpetuating disability through the very act of keeping people disabled. Increasingly, there are Pan-Canadian disability strategies being developed that reflect this by placing responsibility on societal structures, for example, the Pan-Canadian Strategy for Work and Disability with the workplace (Disability, 2019). I have questions about a model of disability where disability is interpreted as a negative that needs to be fixed or cured - where autism is seen as something that can and needs to be treated. A model of disability where Autistic behaviours are seen as symptoms that can and should be eliminated or reduced does not come across as socially equitable for the disabled person. It does not reflect the whole of who I am, how society is involved with my disability, how it is that my environment impacts me, and how all of this plays a role in my health and wellbeing.

This medical model of disability is a model intended to expand or improve functionality of the disabled person, but the focus is on deficit-based treatment (Anderson-Chavarria, 2021; Shyman, 2016). It should be mentioned that there is a focus on intervention that is intended to treat the disabled person's impairments or functioning level, and that this can be considered a benefit (Shyman, 2016). In fact, many medical interventions in the disabled community have been lifesaving (Anderson-Chavarria, 2021). Whatever the intention, when you focus on deficit-based treatment, the emotional wellbeing of the disabled person can suffer. For example, when I am being seen by medical professionals, my autism and the comorbidities that come with it are all that are being focused on, as if it is something to be fixed, that it is something I have to fix. I feel completely overwhelmed and depressed. Oftentimes the traits of being Autistic are viewed negatively as well, and this leads to further mental health issues that impact and interrupt my 
ability to be healthy and productive in my life.

The way that the medical model of disability is structured, there exist some key flaws. It lacks an element of society, and the impact that society and the environment have on someone's disability. The medical model of disability does not recognize society as a key player in the wellbeing of disabled people and how they function in society. As Berghs and colleagues (2016) wrote in Implications for public health research of models and theories of disability: a scoping study and evidence synthesis, "The medical model could be seen as especially weak in conceptualizing comorbidities or multimorbidities, which is at odds with the idea that many people will possibly experience various forms of impairment during their lifetime"(p. 53).

I notice there are also a lot of extra costs associated with a medical model of disability such as investments into technologies and research to treat impairments that the autism community experiences based on the function of the medical model. When I am being treated for my deficits, rather than an adaptation of my environment, which could be more physically attainable and cost effective for myself, I feel pathologized. I am paying for medication, communication training, physical therapy and personal training, counselling, and equipment. I feel as if the medical model of disability is used to justify large investments in areas such as pharmacology, research, and technology - when it could be better for society as a whole, if like I said, adaptations were made in the environment of the Autistic person. Another way in which the medical model falls short, is in the lack of focus on reaching a level of equality between the disabled person and the rest of society. Reaching an equal level of social inclusion does not seem to be a goal in the medical model of disability when the focus remains on treating a disabled person's deficits. It seems to be a rather unfortunate and deterministic model in deciding that the deficits a disabled person has prevent them from becoming equal in society. Furthermore, the frame of reference for the medical model of disability is that of an able-bodied person, rather than that of the disabled person's frame of reference. Thus, with this model, social balance becomes something unlikely to occur and begs the question, how can disabled people and the barriers they face be seen within the context of equity if it is not being seen from their perspectives?

Which brings me to an alternative model of disability whereby a person's disability is seen as a difference and neutral in society, rather than being deficit-based, or seen as negative (Kapp, 2019): a social model of disability. In a social model of disability, the core tenet is that it is through the manner in which society succeeds and or fails to accommodate disabled people that people are disabled and barriers are erected (Berghs et al., 2016). In this model of disability the way to success and equality is to change the relationship between society and the Autistic or disabled person, rather than forcing them to change themselves. To be more clear, this problem is not localized to only the Autistic person or the individual with disability, instead it requires society to enact the changes that need to take place to create an inclusive environment.

The social model of disability has been around for many decades, and begun as a movement in the 1970s (Shakespeare, 2006). There were many international disabled movements 
focused on overturning the medical model of disability (Commonwealth Disabled People's Forum, n.d.), and in 1979 the only multi-disability organization in Canada formed (Canadian Council of Disability [CCD], n.d.). It was called the Coalition of Provincial Organizations of the Handicapped $(\mathrm{COPOH})$, and a headquarters was established in Winnipeg, Manitoba (CCD, n.d.). Society is moving in a more inclusive direction in a lot of areas. There has been a stronger push from the disability rights movements for governments, institutions and organizations to incorporate a social model of disability further into policy. Having said that, this "push" towards inclusivity has been occurring for decades and policy is slow to adapt change.

It's not surprising that groups and individuals would want more inclusive practices in policy and society. I have seen many Autistic movements and organizations on social media for these very things. What is surprising is that the medical model of disability is still used today when people have been advocating for change for many decades. Autistics and people with disabilities prefer the social model of disability over the medical model of disability because it recognizes the systemic and institutional barriers that disabled people face (Botha et al., 2021; Bury et al., 2020; Zolyomi et al., 2019). In terms of autism, the medical model is limited when dealing with the various symptoms, severities, and many treatment options available when accessing services (Singh, 2016). The social model of disability identifies derogatory attitudes and social exclusion in the environment of Autistic and disabled communities in order to shape that environment to be more inclusive. For example, for myself and many Autistic Canadians, the use of person-first language to identify Autistic people instead of identity-first language is especially harmful (Botha et al., 2021; Bury et al., 2020; Zolyomi et al., 2019). Person-first language follows the deficitbased medical model of disability (Anderson-Chavarria, 2021), and ends up dissociating the person from their autism by saying "Person with autism." Person-first language attaches a negative value to disability by separating it from the person (Botha et al., 2021). Society does not use personfirst language when traits are highly valued, for example, we don't say "person with intelligence", rather we say "intelligent person." This is an aspect where a social model of disability recognizes derogatory attitudes in society and adjusts to be more inclusive in comparison to the medical model.

Even the social model of disability has its drawbacks, however. Its main component is that disability remains a social construct, and the question becomes, if nothing else is considered in the model, is this model too narrow of a concept (Samaha, 2007)? As much as a social model of disability identifies systemic barriers and derogatory attitudes towards Autistic people, the model does little to address the physical aspects of an Autistic person's impairment (Lawson \& Beckett, 2021). I feel like the extensive list of comorbidities that come with many autism spectrum diagnoses is poorly attended to in a social model of disability. For these pain and impairment issues, the social model of disability is not equipped to plan intervention and treatment options that many health issues require. Another downside is that the social model of disability is that it is not widely applicable within the context of intersectionality of race, gender, and sexuality. In fact, it has been criticized for positioning disabled people unified into one group (Oliver, 2013). While the social model of disability is meant to address social exclusion of the disabled community from society, it struggles beyond that scope (Samaha, 2007). 
So if the medical model of disability does not address society and the environment's role in a person's disability, and the social model of disability does not reflect the impacts of intersectional identities and impairment needs of the disabled person, then the question becomes, is there something more encompassing that can be used in their places? Fortunately, the answer is yes and in many countries this alternative model is already being used.

The World Health Organization published a new model of human functioning and disability in 2001 called the International Classification of Functioning (ICF) to update its previous 1980 International Classification of Disabilities Impairments and Handicaps (ICDIH) (Stewart \& Rosenbaum, 2003). The updated model of human functioning and disability resolved some

problematic and negative language around handicap and disability, as well as the somewhat narrow and limiting approach to consistent and chronic disabilities (Stewart \& Rosenbaum, 2003). The ICF is a multipurpose classification system that was designed to be universal and use neutral language surrounding disability and health while existing in the social, cultural, environmental and physical contexts of persons with disabilities (Üstün, n.d.). For example, no distinction is made between a mental or a physical health condition and all conditions are considered equally (Üstün, n.d.).

Not only is the ICF a multipurpose classification system that is universal and neutral in its language, it "is a framework for describing and organizing information on functioning and disability. It provides a standard language and a conceptual basis for the definition and measurement of health and disability" (Üstün, n.d., p. 1). That means when it is used universally, it can be used for people who are disabled as equally as those who are able-bodied with no distinction between. The ICF is being used in many countries who have ratified the Convention of Persons with Disabilities, countries such as Germany, Switzerland, South Africa, Chile, Brazil, the Netherlands, and Mexico (de Camargo \& Snyman, 2019; Gesley, 2017; Hollenweger, 2011; Yañez, 2019). While some parts of the ICF are being looked at in some universities and rehabilitation centres in Canada, it has not been accepted as a model of human functioning and disability for the country as of yet (de Camargo \& Snyman, 2019).

Criticisms of the ICF include that it still takes from the medical model of disability, perhaps too much so - and applications of the ICF model in health research is limited (Berghs et al., 2016). Another drawback is that the ICF has been criticized for not theorizing some of its components thoroughly enough, and overlooks the impacts of poverty and inequity on disability impairments (Berghs et al., 2016). Despite these criticisms, one of the reasons that I see the ICF as a complimentary model of functioning for use in Canada is grounded in the fact that it resolves a lot of the problems that both the medical and social model of disability have had over the past decades. Its universal and neutral language addresses disability and functioning in a way that does not focus on the negative or abnormal aspects of a person's ability, which the medical model is criticized for (Üstün, n.d.). In addition to addressing the criticism of the medical model of disability, the ICF addresses some of what is lacking in a social model of disability, especially as it pertains to impairment and functioning. For example, the ICF has a domain that recognizes the role that body functions play in health and disability, whereas the social model is not structured this way. In addition, the ICF commits focus on the personal and environmental aspects that play a role in the 
functioning of the person. For instance, the ICF is built to universally recognize body functions, body structures, activities, participation and environmental factors (Üstün, n.d.). Body function and body structure are how each component of the body is capable of functioning and what those components are respectively. The ICF also considers activities and participation that cover things such as communication, mobility, self care, interpersonal relationships and interaction, community, social and civic life and more. Environmental factors include services, systems, and policies, attitudes, natural and man-made changes to environment, products and technology, and support and relationships (Üstün, n.d.). The last type of factor is personal factors, and has to do with what the disabled or Autistic person wants or needs to feel meaning in their life.

With the ICF, there is the health condition as well as all of the factors surrounding the health condition including the person themselves built into the model. If one factor is improved upon, it can and is likely to benefit another area. For example, if changes to the environment are made in relation to the health condition, then an area such as activity or participation will also be impacted. Or, if systemic changes were made in the way that language was used in society to reflect the autistic community's desire to use Identity-first language, a positive change might occur not only in the Environmental factors (policies, attitudes), but also in Participation factors (interaction, civic life, community) and Personal factors.

So the ICF is a more universal model of functioning and disability health that has many additional components than the previous medical or social model of disability. The language that the ICF uses is neutral in its description of health, functioning and disability, and it is intended to be used internationally. Because it involves more aspects and factors of human health and disability, it is well-suited to not only be a classification tool but also to be used in policy and research as well (Stewart \& Rosenbaum, 2003). There can be much benefit to Autistic people and persons with disabilities, in policy makers considering an approach that involves neither of the polarizing models of disability discussed above, and the ICF works in tandem with the UN Convention on the Rights of Persons with Disabilities on disability data and social policy modelling. As stated in the ICF Overview, "[The ICF] provides a valuable information framework for monitoring mechanisms in order for countries to report to the UN on progress against the Convention's targets" (Üstün, n.d., p. 7).

Currently, in environments like hospitals, public service buildings, and spaces the government runs, it can be difficult or stressful to fully access the services for Autistic people or people with disabilities. It is essential to have the government engage, and have a deeper understanding of issues like this, and accommodate the needs of the autism community and bring us closer to equity in services and realize our rights more fully. Education and training are necessary in reducing stereotypes perpetuated about autism and to increase understanding of the complex needs of Autistic people in order to accommodate them in public spaces where proper accommodations are currently not in place.

Inclusive social policies happen when we address how Autistic people or people with disabilities are being denied full participation, exposed to prejudicial attitudes, and subject to inaccessible social activities. These are real issues which create the current barriers that disable 
Autistic people. Through a healthy implementation of a full ICF model in Canada that aligns with the UN's Convention on the Rights of Persons with Disabilities of which Canada has ratified, we are much more likely to make these universal and inclusive policies happen, and be that much closer to an equitable future for the autism community and those advocating for them.

\section{ORCID iD}

Rebekah Kintzinger (iD https://orcid.org/0000-0003-1302-8291

\section{References}

Council of Canadians with Disabilities. (n.d.). History. http://www.ccdonline.ca/en/about/history Anderson-Chavarria, M. (2021). The autism predicament: Models of autism and their impact on autistic identity. Disability \& Society, 1-21. https://doi.org/10.1080/09687599.2021.1877117

Berghs, M., Atkin, K., Graham, H., Hatton, C., \& Thomas, C. (2016). Scoping models and theories of disability. In Implications for public health research of models and theories of disability: A scoping study and evidence synthesis. NIHR Journals Library. https//www.ncbi. nom.gov/books/NBK378951/

Botha, M., Hanlon, J., \& Williams, G. L. (2021). Does language matter? Identity-first versus person-first language use in autism research: A response to Vivanti. Journal of Autism and Developmental Disorders, https://doi.org/10.1007/s10803-020-04858-w

Bury, S. M., Jellett, R., Spoor, J. R., \& Hedley, D. (2020). "It Defines Who I Am" or "It's Something I Have": What language do [Autistic] Australian adults [on the Autism Spectrum] prefer? Journal of Autism and Developmental Disorders. https://doi.org/10.1007/s10803-020-04425-3

Commonwealth Disabled People's Forum. (n.d.) https: / / commonwealthdpf.org/

de Camargo, O. K., \& Snyman, S. (2019). The ICF: Themes and tools for the education of health professionals. In ICF: A Hands-on Approach for Clinicians and Families (1st ed., p. 192).

Disability, W. in C. (DWC) S. C. (2019). Moving forward together: A pan-Canadian strategy for disability and work. 19.

Gesley, J. (2017). Germany: Act to strengthen the disabled's participation in society enters into force. Global Legal Monitor, 2.

Kapp, S. K. (2019). How social deficit models exacerbate the medical model: Autism as case in point. Autism Policy and Practice, 26.

Lawson, A., \& Beckett, A. E. (2021). The social and human rights models of disability: Towards a complementarity thesis. The International Journal of Human Rights, 25 https://doi.org/ $10.1080 / 13642987.2020 .1783533$

Ministry of Children, Community and Social Services. (2019, September 11). Ontario Autism Program. Ontario.Ca. https://www.ontario.ca/page/ontario-autism-program

Oliver, M. (2013). The social model of disability: Thirty years on. Disability \& Society, 28(7), 1024-1026. https://doi.org/10.1080/09687599.2013.818773

Samaha, A. M. (2007). What good is the social model of disability? The University of Chicago Law Review, 74(4), 1251. https://doi.org/10.2307/20141862

Shyman, E. (2016). The reinforcement of ableism: Normality, the medical model of disability, and humanism in applied behavior analysis and ASD. Intellectual and Developmental Disabilities, 54(5), 366-376. https://doi.org/10.1352/1934-9556-54.5.366

Singh, J. S. (2016). Parenting work and autism trajectories of care. Sociology of Health \& Illness, 38(7), 1106-1120. https://doi.org/10.1111/1467-9566.12437

Stewart, D., \& Rosenbaum, P. (2003). The International Classification of Functioning, Disability, and Health (ICF): A global model to guide clinical thinking and practice in childhood disability. CanChild. https://canchild.ca/en/resources/182-the-international-classification-of-functioningdisability-and-health-icf-a-global-model-to-guide-clinical-thinking-and-practice-in-childhooddisability 
Üstün, T. B. (n.d.). The ICF: An overview. World Health Organization. https://www.cdc.gov/nchs/data/ icd/icfoverview finalforwho10sept.pdf

Yañez, M. (2019). Implementation of ICF in Mexico. WHO Collaborating Centre Voor de Familie van Internationale Classificaties (FIC) in Nederland. https:// whofic.nl/implementation-of-icf-in-mexico

Zolyomi, A., Begel, A., Waldern, J. F., Tang, J., Barnett, M., Cutrell, E., McDuff, D., Andrist, S., \& Morris, M. R. (2019). Managing stress: The needs of Autistic adults in video calling. Proceedings of the ACM on Human-Computer Interaction, 3(CSCW), 1-29. https://doi.org/10.1145/3359236 